The Geneva Papers on Risk and Insurance, 16 (No. 61, October 1991), 448-461

\title{
Strategic Planning in the Malaysian Insurance Industry
}

\author{
by A. R. M. Zabid*, S. Kamaruddin**, O. Maizon*** and R. A. Ghaffar*
}

\begin{abstract}
This article examines the extent of planning and the key essential characteristics of planning in the Malaysian insurance industry. A survey was conducted with the support of the Malaysian Insurance Institute. A total of 59 insurance companies involved in life, general and composite businesses were given the questionnaire. A total of 36 companies responded the questionnaire. The findings showed that all the insurance companies conducted formal planning. However, only one quarter have a planning unit/section. The extent of planning conducted varies according to the type of insurance business and existence of planning unit/section. The Chief Executive Officers are highly involved in the planning activities. Planning activities are focused at the functional level, short term, and the medium term. There are more firms conducting an internal analysis than an external analysis. As for corporate objectives, underwriting profit is rated as most important and the sum insured as least important. It was also found that nearly $89 \%$ of the firm pursed a combination strategy of growth and stability. Overall, nearly $75 \%$ considered the effectiveness of the planning system in achieving corporate goals, and about $37 \%$ considered it as most important towards better performance. Implications of the findings are also discussed.
\end{abstract}

\section{Introduction}

Planning is one of the fast developing business concepts. According to Gluck et. al. (1980), the evolution of strategic planning evolved through four sequential phases. In the first phase, the planning process focused on budget planning, that is meeting the functional annual budget and schedules. In the second phase, strategic planning focuses on short or medium term. The resource allocation process continues to be 'static'. As the environmental dynamics changes rapidly, the strategic planning focus adds upon understanding the "external orientation'. At this stage, the organisation seeks to achieve the strategic fit between the

* Lecturers in the Faculty of Economics and Management, Universiti Pertanian Malaysia.

** Associate Professor, Faculty of Business Management, Universiti Kebangsaan Malaysia.

*** General Manager, Malaysian Insurance Institute.

The authors wish to thank the Malaysian Insurance Institute for support. 
internal and external environment. The value system developed is to 'think strategically'. It is at this phase that the concept of strategic planning evolved. The first two phases of planning have often been referred as traditional planning (first phase) and long range planning (second phase). The fourth phase is where the strategic planning systems and processes are fully developed which result in the 'strategic management' orientation. The focus is creating the future, as opposed to anticipating the future in the third phase. Although the concept of planning has evolved through various phases, the planning practices in various firms, industry and nations, vary. Walker (1980) contends that all the major insurance companies in U.S. were in the second phase. This is supported by the findings of Aylor and Cummins (1985) that several U.S. property liability insurance companies were in the first and second phase. Only a handful have progressed into the third phase. In the European insurance industry, Grosjean (1985) concluded that the majority of the organisations were in the earliest stages of evolution. In another study of Australian insurance industry, Sharp (1985) concluded that the industry falls into the second phase. These findings clearly suggest that the evolution of planning in the insurance industry varies by firm, industry and nation. While this may be true, one basic question guiding this study is to what extent does the evolution of planning vary in the Malaysian insurance industry. Do planning practices in Malaysia falls under the first, second or third phase? Are there firms that fall into various stages of planning or otherwise? Finally, what are the key essential characteristics of planning in the Malaysian insurance industry? This paper, therefore, focuses on these key research questions.

Although strategic planning is widely researched in the developed countries like U.S., U. K., France and Canada, little research is conducted on the topic in developing countries, particularly Malaysia. This is particularly important as developing countries too have large and sophisticated business mix which requires advanced management tools like planning. Further, this study would enhance the generalisation of the planning concepts and practices as found in most texts or articles written in the developed countries. This research is also important as it adds greater knowledge on the art and science of planning management in the developing countries. While it may be argued that planning is not directly related to the level of economic development of a country, it is inevitable that the degree of planning sophistication and characteristics are related directly to the business growth. Further, it is argued that since planning practices may vary across firms/organisations, the extent to which the planning practices differ will create an impact on the style of managing such organisations. As such, sophisticated managerial techniques developed in the western literature may appear to be inappropriate for firms in such situations. Training in management should then focus on the next immediate step rather than on the more sophisticated tools. For instance, if it is assumed that planning is in the second phase, the focus should be towards developing in the third phase as opposed to the fourth phase. The incremental approach is highly recommended in order to avoid the strategic pitfalls of corporate failures. Finally, this study adds greater insights into the plethora of literature on planning in the insurance industry, and specifically on the insurance industry in Malaysia.

\section{The Malaysian insurance industry}

The insurance industry has developed in Malaysia since the early part of the eighteenth century when the British and other foreign countries began their trading and other economic activities in the country (De Dios, 1988). However, it was not until 1948 when 
legislation of life insurance was first introduced in this country. In 1949, legislation on general insurance business was introduced. Such legislation could not control the rapid development of insurance companies. In 1961, the Malaysian Government introduced a legislation requiring new companies with a minimum paid-up capital of $M \$ 1$ million. With the creation of Malaysia in 1963, the Insurance Act of 1963 was enacted under the Ministry of Finance. The Governor of the Central Bank was appointed as the Director General of Insurance in May 1988 under the Insurance Act of 1963

Although the history of the insurance industry is as old as the banking sector, the industry remained small compared to other financial institutions. At the end of 1988 , the total assets of the insurance industry amounted to $M \$ 7$ billion or $3.2 \%$ of the total assets of the Malaysian financial system. To date, there are 59 underwriting insurance businesses in Malaysia under the Insurance Act of 1963. This comprises two life insurance companies, 41 general and 16 composite (transacting both life and general business). This was a reduction compared to 65 in 1980 due to the restructuration of the industry consistent with the increasing domestic participation as reflected in the New Economic Policy. In 1980 , there were 26 foreign owned companies, and by 1988 the number was reduced to nine. This was done through the reincorporation and merger with domestic companies. This process had also increased the capitalisation of the insurance industry from $M \$ 64.9$ million in 1976 to M\$709 million by the end of June 1988. Foreign-based companies owned M\$207 million or $29.2 \%$ of the total paid-up capital in June 1988. The continuous growth in the capitalisation is also consistent with the growth in human resources. In 1980, the industry provided employment for more than 8,800 people. In 1988 , there were more than 10,900 people employed in the industry. The number of life insurance agents increased from 13,784 in 1980 to 43,740 in 1988 . The number of professional/academic personnel increased from 375 in 1980 to 1,892 in 1988 . Nonetheless, the industry is facing a shortage of professionals, particularly in insurance and actuaries. By 1988, there are only 23 qualified actuaries in the country.

With regards to the total premium income, the industry acquired more than $\mathrm{M} \$ 2$ billion in 1988 as compared to $M \$ 0.9$ billion in 1980 . This shows an increasing contribution of the industry towards the national economy, particularly when it contributed $1.9 \%$ of the GDP in 1980 as compared to $3.2 \%$ in 1988 . The growth in the total premium income was attributed to the greater contribution of life insurance (55\%) as compared to the non-life business in 1988. In life insurance, the new annual premiums increased by $14.3 \%$ to $\$ 278$ million in 1988 as compared to 1987 , while the number of new policies issued recorded an increase of $10.4 \%$ to 408,525 . The life insurance industry also experienced in the termination of policies during 1988 by $6.6 \%$ to $\mathrm{M} \$ 7$ billion. The proportion of sums insured terminated due to forfeitures declined by $16 \%$ to a share of $51 \%$ compared to $60.7 \%$ in 1987 .

In the general insurance business, the performance of the industry improved with an increase in written premium to $\mathrm{M} \$ 1.25$ billion in 1988 as compared to $\mathrm{M} \$ 777$ million in 1980. The reinsurance premium ceded overseas amounted to $M \$ 335$ million in 1988 as compared to $M \$ 190$ million in 1980 . This resulted to an increase in the net retained premium income of $\mathrm{M} \$ 915$ million in 1988 as compared to $\mathbf{M} \$ 587$ million in 1980 . The total gross claims also increased from $\mathbf{M} \$ 306$ million in 1980 to $\mathbf{M} \$ 649$ million in 1988 . In terms of underwriting expericnce, the general insurance industry recorded slight improvement with a net loss of $M \$ 53$ million in 1988 as compared to $M \$ 59$ million in 1987 and M\$69 million in 1986. However, the underwriting losses were offset by other sources of 
income and capital gains resulting in a net operating profit of M $\$ 49.4$ million in 1988 as compared to $\mathrm{M} \$ 43$ million in 1987 and $\mathrm{M} \$ 9.9$ million in 1986.

Overall, it may be noted that the growth and development of the insurance industry has been encouraging in Malaysia. The economic cycles have affected the industry's performance. Nonetheless, the industry has considerable scope for expansion considering the relatively large untapped insurance potential within the economy as only $10 \%$ of the insurable Malaysian has a life policy. The general insurance business has room for expansion in view of the degree of underinsurance of property and income loss, greater need for the services of risk management, and the greater need for insurance in the specialised areas such as marine, aviation and energy related risks.

\section{Methodology}

\subsection{Sample}

The findings of this research are based on a survey conducted by the Malaysian Insurance Institute. A total of 59 insurance companies involved in life, general and composite insurances were given questionnaires relating to planning practices. This was done through the mail survey. The questionnaire was addressed to the Principal Officers (Chief Executive Officers) of these insurance companies. After one month, a total of 36 companies responded the questionnaire, representing a response rate of $61 \%$. The data was analysed based on this as further effort to increase the response rate proved futile. Table 1 shows the organisation and managers' profile of the participants in the survey.

\subsection{Questionnaire}

A questionnaire was developed, based on the literature on planning and discussions with the insurance professionals in Malaysia. This is to ensure that the relevant and appropriate questions are examined. Questions relating to the nature and type of planning, mission, objective, internal and external analysis, and strategies were asked in English. While most of the questions were structured, some questions were on an interval scale of 1 $=$ Not important at all, to $6=$ Very important.

\section{Table 1}

Profile of Respondents in Planning

\section{Managers' Background}

1. Job Title

$\begin{array}{lr}\text { Principal Officer } & 72.2 \% \\ \text { Director } & 8.3 \% \\ \text { Manager } & 19.4 \%\end{array}$

2. Job Specialization

Human Resources $\quad 2.9 \%$

Accounting/Finance $\quad 14.3 \%$

Marketing / Sales $\quad 20.0 \%$

Others $\quad 62.9 \%$ 
3. Age

Below 35 years

$2.8 \%$

35 - 39 years

$25.0 \%$

40 - 44 years

$30.6 \%$

45 and above

$41.7 \%$

4. Highest Qualification

Diploma

$17.1 \%$

Degree

$22.9 \%$

Professional

$28.6 \%$

Others

$31.4 \%$

5. Ethnic Group

Malays

$26.5 \%$

Chinese

$52.9 \%$

Indians

$11.8 \%$

Others

$8.8 \%$

6. Salary

$\begin{array}{lr}\text { Less than } \$ 4,000 & 2.9 \% \\ \$ 4,000-\$ 6,999 & 20.6 \% \\ \$ 7,000-\$ 9,000 & 44.1 \% \\ \text { More than } \$ 10,000 & 32.4 \%\end{array}$

Company's Background

7. Type of Business

General Insurance

$77.8 \%$

Composite Insurance

$22.2 \%$

8. Paid-Up Capital

Less than $\$ 10$ million

$40.6 \%$

$\$ 10-\$ 19$ million

$31.3 \%$

More than $\$ 20$ million

$28.1 \%$

9. Total Sales Premium

Less than $\$ 19$ million

$24.1 \%$

$\$ 20$ - \$39 million

$31.1 \%$

More than $\$ 40$ million

$44.8 \%$

10. Ownership Stucture

Locally owned

$78.1 \%$

Foreign owned

$18.8 \%$

$50-50 \%$ owned

$3.1 \%$

11. Fulltime Employees

Less than 100

$53.5 \%$

100-199

$26.7 \%$

More than 200

$20.0 \%$ 


\section{Findings and discussion}

\subsection{Nature and type of planning}

The findings of this survey revealed that all insurance companies $(\mathrm{N}=36)$ conducted formal planning in their organisations. However, $80.6 \%$ conducted planning at the functional level, $77.8 \%$ conducted planning at the business level, and three-quarters conducted planning at the corporate level.

With respect to the planning horizon, $55.2 \%$ of the firms conducted it at the corporate level beyond three years, while at the business level, $81.3 \%$ of the firms conducted planning between 1-3 years. At the functional level, more than half of the firms conducted planning between 1-3 years, and nearly $40 \%$ conducted it for less then one year (See Table 2). This clearly suggests that planning is more frequently conducted for a duration of between 1-3 years. In another question, $88.2 \%$ responded that they frequently used such planning horizon. About $84 \%$ of the firms responded that they frequently conducted planning for a duration of less than one year. As such, planning horizon for a duration of more than 3 years appears to be rarely considered. Nearly $64 \%$ claimed that they rarely conducted long term planning. This implies that planning in the insurance industry is focused towards short and medium term plans.

Table 2

Duration of planning horizon at each level

\begin{tabular}{lccc} 
Planning Horizon & Corporate & Business & Functional \\
\hline Less than 1 year & $10.3 \%$ & $9.4 \%$ & $39.3 \%$ \\
$1-3$ years & $34.3 \%$ & $81.3 \%$ & $57.1 \%$ \\
More than 3 years & $55.2 \%$ & $9.4 \%$ & $3.6 \%$ \\
\cline { 2 - 4 } & $100.0 \%$ & $100.0 \%$ & $100.0 \%$ \\
\hline
\end{tabular}

Table 3

Managers involved in planning activities

$\begin{array}{ll}\text { Board of Directors } & 33.3 \% \\ \text { CEOs } & 91.7 \% \\ \text { Divisional Managers } & 91.7 \% \\ \text { Functional Managers } & 69.4 \% \\ \text { Corporate Planners } & 26.7 \%\end{array}$

This planning horizon trend appears to be consistent with the findings of Grosjean (1985) on the European insurance industry and that of Sharp (1985) on the Australian and U.K. insurance companies. It also implies the importance of planning in the insurance industry, and that short or medium range plans are the primary emphasis of such firms. This is related to the cautious and conservative approach of most insurance companies (Grosjean, 1985). The lack of planning expertise and professionals is another contributory factor 
towards this planning behaviour (Grosjean, 1985; Frederick, 1983). The size of the business operation is another factor inhibiting towards this planning pattern (Curtis, 1983). This is due to the high costs of engaging specialised skills which is perceived as more important than the key functional areas of marketing or finance.

Although most respondents claimed having conducted formal planning, only one quarter have a planning unit or section or department. This proportion is smaller compared to the U.S. firms $(71 \%)$ or European firms (79\%) (Aylor and Cummins, 1985; Grosjean, 1985). However, this proportion is larger than in the Australian insurance industry $(12 \%)$ or U.K. insurance industry (15\%) (Sharp, 1985). In the planning department, $62.5 \%$ of these firms had 3 employees and the rest had more than 3 employees. Nearly $59 \%$ of these firms have set up their planning unit less than 2 years ago. These findings are much smaller compared to the U.S. or European firms which is reflected by the size of the insurance firms in those countries. It suggests that planning is still a recent phenomenon in the Malaysian insurance industry.

With regard to the planning process, the majority of the respondents claimed it to be highly formalised, consistent with the above findings. The respondents also perceived that it was more towards the creative process as opposed to the mechanistic one. This is related to the short range focus, while the creative phenomenon is related towards the strategic approach in the planning process. However, the internal focus reasoning as found by Ayler and Cummins (1985) does not hold true in the Malaysian insurance industry.

While the planning process may be short ranged, this survey found that $91.7 \%$ of the Chief Executive Officers (CEOs) and divisional managers were involved regularly in the planning activities. Nearly $69.4 \%$ of the functional managers and about one third of the board members were regularly involved (See Table 3). As such, CEOs are primarily involved in such activities. In Malaysia, $75 \%$ of the respondents also indicated that their CEOs were heavily involved. This is higher compared to U.S. insurance companies $(46 \%)$ (Aylor' and Cummins, 1985). This indicates the higher level of commitment to strategic planning in Malaysia as contrasted to the U.S. firms. Although the support, commitment and involvement of CEOs in Malaysia are relatively higher than in U.S., it does not dispute the fact that the plans were short range in focus. This is probably due to the short term concern by the CEOs in the Malaysian insurance industry. This is true as the short term plans are often reviewed on a monthly $(55.2 \%)$ basis than on a quarterly $(31.0 \%)$ basis. Medium range plans are often reviewed twice a year $(39.4 \%)$, while long term plans are reviewed annually $(70.8 \%$ ) (See Table 4 ). This implies that the longer the planning

\section{Table 4}

Frequency review of planning horizon

\begin{tabular}{lrrr} 
& Less than 1 year & $1-3$ years & More than 3 years \\
\hline Monthly & $55.2 \%$ & $15.2 \%$ & - \\
Quarterly & $31.0 \%$ & $27.3 \%$ & $4.2 \%$ \\
Semi-annually & $10.3 \%$ & $39.4 \%$ & $25.4 \%$ \\
Annually & $3.4 \%$ & $18.2 \%$ & $70.8 \%$ \\
\hline & $100.0 \%$ & $100.0 \%$ & $100.0 \%$ \\
\hline
\end{tabular}


horizon, the less frequent the plans are reviewed. Once again, this reinforces the belief that the insurance companies focus on short or medium term activities.

\subsection{Corporate mission and objectives}

Corporate mission statements are fundamental in setting the direction of the company, reflecting its philosophy and raison d'être of an organisation's existence. In this survey, $75 \%$ of the firms claimed that they have a corporate mission. While this may be true, nearly $69 \%$ of the firms reviewed such mission statements. About $81.3 \%$ indicated that they inform their employees of the corporate mission. This suggests that such statements are communicated through the organisation so as to enhance the understanding, commitment and support of the staff in the organisation.

As for corporate objectives, the majority $(28.6 \%)$ of the firms focus on medium term ( 1 - 3 years). Nearly $11.4 \%$ focus on long term (more than 3 years), and $8.6 \%$ focus on short term (less than 1 year). About one-third focus on a combination of short, medium and long term objectives. As such, insurance companies emphasise on medium term or a combination time span (See Table 5).

Table 5

Time span for setting corporate objectives

$\begin{array}{lr}\text { Short term } & 8.6 \% \\ \text { Medium term } & 28.6 \% \\ \text { Long term } & 11.4 \% \\ \text { Combination of short and medium } & 14.4 \% \\ \text { Combination of short and long } & 2.9 \% \\ \text { Combination of short, medium and long } & 34.3 \%\end{array}$

Nearly $94.4 \%$ of the respondents indicated that the objectives are made known to their employees. This clearly suggests that such objectives are communicated through the employees. This is important to enhance the level of support and commitment of the employees.

The findings of this survey also revealed that the Malaysian insurance companies rated underwriting profit (mean $=5.69$ ) as the most important objective. Investment profit $($ mean $=5.64)$, net premium $($ mean $=5.61)$ and return on investment $($ mean $=5.47)$ were considered quite important objectives in the industry. However, the sum insured (mean = 4.03) was rated as least important, while the number of clients (mean $=4.74$ ) and market share $($ mean $=4.79)$ were rated as of lower importance (See Table 6$)$. This clearly revealed that the Malaysian insurance companies focus on the profitability growth as compared to others. In the Australian insurance industry, Sharp (1985) found that the objectives were also largely financial, although some companies also considered social factors. Underwriting profit was also mentioned by the Australian firms in their corporate objective. The greater importance given to net premium as opposed to return on investment suggests that the basic emphasis of Malaysian insurance companies is towards the corporate survival instead of the shareholders interests. The findings, therefore, imply that the Malaysian 
insurance firms were short range oriented in pursuing their corporate objectives. Further, it should be noted that the greater importance attached to underwriting profit was largely from the general insurance business and not from the composite insurance firms. Similarly the general insurance firms considered investment profit as more important than the composite companies. This is reasonable as the composite companies have the life insurance business to compensate, as such the net premium, number of clients, return on investment and market share are important characteristics of corporate objectives.

\section{Table 6}

Corporate objectives of insurance companies

$\begin{array}{lccc} & \text { Mean } & \text { S. D. } & \text { Rank } \\ \text { Underwriting profit } & 5.69 & 0.58 & 1 \\ \text { Investment profit } & 5.64 & 0.34 & 2 \\ \text { Net premium } & 5.61 & 0.55 & 3 \\ \text { Return on investment } & 5.47 & 0.51 & 4 \\ \text { Cash flow } & 5.33 & 0.72 & 5 \\ \text { Assets growth } & 5.31 & 0.75 & 6 \\ \text { Gross premium } & 5.31 & 0.69 & 6 \\ \text { Market share } & 4.79 & 1.27 & 8 \\ \text { Number of clients } & 4.74 & 1.24 & 9 \\ \text { Sum insured } & 4.03 & 1.53 & 10\end{array}$

\subsection{Internal and external analysis}

An internal analysis provides an assessment of the key factors within the organisation, thus leading to the identification of the corporate strengths and weaknesses. In this survey, $94.4 \%$ of the firms indicated that they conducted such analysis. Table 7 shows the frequency of conducting such analysis.

\section{Table 7}

Frequency in conducting internal and external analysis

Internal Analysis

$\begin{array}{lc}\text { Frequency } & \text { Percent } \\ \text { Weekly } & - \\ \text { Monthly } & 11.8 \% \\ \text { Quarterly } & 35.3 \% \\ \text { Semi-Annually } & 17.6 \% \\ \text { Annually } & 35.3 \%\end{array}$

External Analysis

$\begin{array}{lr}\text { Frequency } & \text { Percent } \\ \text { Weekly } & 3.0 \% \\ \text { Monthly } & 6.1 \% \\ \text { Quarterly } & 30.3 \% \\ \text { Annually } & 60.6 \%\end{array}$

In contrast, the external analysis provides an assessment of the potential opportunities and threats in the business environment. About $91.7 \%$ of the Malaysian insurance firms conducted such analysis. Table 7 shows the frequency of external analysis. 
The findings clearly imply that more firms conducted internal analysis than an external one. This is reasonable as $8.3 \%$ of the firms claimed that in developing their company plans, they focused on internal issues, which presumably are more critical than the external issues. Table 7 also suggests that both the internal and external analysis are frequently conducted on a annual or quarterly basis.

From Table 8 , it may be discerned that the divisional managers were generally involved in the internal analysis, while the CEOs were more involved in the external analysis. This is reasonable as one of the roles of the CEO involves monitoring the external environmental dynamics (Zabid, 1987). The greater involvement of divisional managers are closely related to the fact that they were focused towards the internal issues, which is one of the key roles and responsibilities of these managers. Nonetheless, both the CEOs and divisional managers are highly involved in the internal and external analysis.

\section{Table 8}

Managers involvement in internal and external analysis

Internal

People involved

CEOs

Divisional managers

Functional managers

Corporate planners

Executives
Percent

$83.3 \%$

$86.1 \%$

$77.8 \%$

$11.1 \%$

$38.9 \%$
External

People involved

CEOs

Divisional managers

Functional managers

Corporate planners

Others
Percent

$86.1 \%$

$72.2 \%$

$55.6 \%$

$13.9 \%$

$16.7 \%$

Table 9

Tools used in internal and external analysis

\begin{tabular}{lclc} 
Tools & & \multicolumn{2}{c}{ External } \\
& Percent & Tools & Percent \\
Financial ratios & $80.6 \%$ & Environmental scanning & $44.4 \%$ \\
SWOT & $41.7 \%$ & ETOP & $47.2 \%$ \\
Portfolio matrices & $27.8 \%$ & Scenario & $58.3 \%$ \\
& & Econometric forecasting & $16.7 \%$
\end{tabular}

With reference to the tools used in the internal and external analysis, table 9 shows that the Malaysian insurance companies generally used the financial ratios $(80.6 \%)$ for the internal analysis. About $42 \%$ indicated using SWOT and $27.8 \%$ mentioned using portfolio matrices. In the external analysis, scenario $(58.3 \%)$ was more commonly used, followed by the environmental threats and opportunities profile $(47.2 \%)$ and environmental scanning $(44.4 \%)$. This clearly suggests that the responding companies used the qualitative techniques more frequently than the quantitative approaches. This is not unreasonable as 
the sophisticated quantitative approaches in the internal and external analysis require specialized expert personnel in the organisation, which may be cost constraint to many insurance organisations. Further, the smaller number of companies with a planning unit or section implies that the industry has limited personnel which deters the organisation's ability to use advanced techniques. This does not imply that the qualitative approach is less accurate but it could certainly improve the analysis of the internal and external environment with more information obtained through various sources.

In examining the internal and external analysis, the findings revealed several key factors identified by the responding firms as important determinants of corporate strengths and weaknesses or opportunities and threats to the organisation. Table 10 and 11 show the selected factors relating to internal and external analysis.

\section{Table 10}

Selected factors determining corporate strengths and weaknesses

Factors

Insurance services

Product / service image and reputation

Company image and prestige

Management personnel

Employees skills and morale

Organisation control systems

Profitability

Investment returns

Insurance professionals

Organisation communication system
Mean

5.75

5.69

5.64

5.56

5.50

5.47

5.42

5.36

5.25

5.25
S.D.

0.55

0.47

0.49

0.50

0.56

0.61

0.65

0.68

0.77

0.65

Rank

\section{Table 11}

Selected factors determining opportunities and threats to the organisation

Factors

DGI policies

Intensity of competition

Government policies

Economic growth

Industry agreements

Technological developments

Ease of entry into business
Mean

5.65

5.50

5.47

5.35

5.32

5.00

4.79
S.D.

Rank

1

2

3

4

5

6

From Table 10, it may be discerned that insurance services are the most important factor. Although insurance professionals are highly needed, it was perceived as of lower importance like the communication system within the organisation. This is reflected by the greater importance attached towards the marketing orientation like the product scrvice 
image and reputation, and corporate image and prestige. In contrast, the responding firms perceived DGI policies as the most important determinant in the external analysis. This is reflected by the perception that the insurance industry is a highly regulated industry. Although the intensity of competition is important, once again the government policies placed an important determinant as compared to the technological developments or industry agreements (self-regulation) (See Table 11). These findings suggest the importance of the political factor in determining the industry's future direction. This is true as the degree of regulation imposed in the industry was perceived relatively higher than the other financial institutions like commercial banks or finance companies. It is also true as the insurance tariffs are regulated by the DGI office. In contrast, although the interest rates are controlled by the Central Bank in Malaysia, the base lending rates are often revised depending on the situation. The insurance tariff has not been revised since 1959. As such, the dynamism appears to be restricted in the insurance industry.

\subsection{Corporate strategy and planning effectiveness}

With regards to the development of corporate strategies, it was found that $88.9 \%$ of the firms pursued a combination strategy of growth and stability. This means that the companies were following towards expansion in certain business, while maintaining a 'no change' strategy for other businesses, like motor insurance. About $8.3 \%$ indicated pursuing only the growth strategy, and $2.8 \%$ pursued only the stability strategy.

This suggests that the Malaysian insurance firms perceived an optimistic outlook of the industry's growth potential, except in certain businesses like motor insurance where the claims ratio appeared to be insupportable. This view is probably influenced by the close relation between economic growth and insurance industry growth, particularly in the general insurance business. Since this correlation is true, the strategic planning approach as practiced by the Malaysian insurance companies appears to be a reasonable and practical one. As such, $55.6 \%$ considered the planning system in achieving the corporate goals as quite effective, while $19.4 \%$ considered it as highly effective. Further, $14.3 \%$ indicated moderately important that the planning process and system have contributed towards improved performance. About $37.1 \%$ considered as most important for better performance. This proportion is higher than in U.S. insurance industry (Aylor and Cummins, 1985). This implies that strategic planning conducted in the Malaysian insurance industry was conducted with greater caution and commitment consistent with the realities of the environmental dynamics, thus adding value towards improved performance. It would also imply the quality of planning practices as evidenced in the Malaysian insurance industry.

\section{Conclusion}

The findings of this study clearly revealed that all the insurance companies conducted formal planning. While this may be true, it cannot be denied that the extent of planning conducted in the Malaysian insurance companies differ, particularly those with a planning unit and those without. As such, it may be not unreasonable to say that there are firms in the insurance industry that fall into the various stages of planning, some in the first phase, a few in the second phase and perhaps a smaller number in the third phase (especially those with a planning unit or section). Another important factor distinguishing between the second and third phase is the extent of the tools used in the internal and external analysis. Since quite a large proportion of the firms focused their plans on both internal and external 
issues. It is, therefore, not inappropriate to consider such firms in the second or third phase. Overall, based on the planning evolution model of Gluck et. al. (1980), it may be considered that the Malaysian insurance industry falls into the second (for the majority) and the third phase (a selected few). It should be noted that the categorisation of the Malaysian insurance industry in the planning evolution model is not the critical factor. What should be the primary focus is the effort towards more effective planning approach which contributes towards improved performance. The Malaysian planning approach has been viewed as highly effective and most important towards better performance. The important role now is to improve the scope and depth of planning practices so that the Malaysian insurance industry can cope with more rapid changes in the 1990s. The key planning characteristics have demonstrated its effectiveness and practicality in coping with the 1980's, however, that could not assure insurance industry against more complex environmental change. With the advent of information technology and computerisation in the insurance industry, the planning behaviour of insurance companies have to be changed in a consistent way with the strategic environmental change.

One important implication of the findings is that much effort is needed to enhance the sophistication of planning development in the Malaysian insurance industry. For instance, internal and external analysis should be conducted more regularly, tools used should be more varied in order to add valuable information pertaining to the planning effort, identification of corporate strengths and weaknesses. Opportunities and threats need to be more objectively determined so that managing through the constraints should be the goal as opposed to managing within the constraints. Finally, to ensure effective implementation of the strategic plans, it should be widely communicated to the employees (that need to know) and develop the level of support, commitment and confidence of the employees. Strategic planning would only be a futile effort unless understood by all involved in achieving the corporate objectives and mission. 


\section{REFERENCES}

AYLOR, C.C., and CUMMINS, D.J. (1985), Strategic Planning in the U.S. Property Liability Insurance Industry, in "Strategic Planning and Modelling in Property Liability Insurance" edited by J. D. Cummins, U.S. A, Kluwer Academic Publishers, 1-77.

CURTIS, D. A. (1983), Strategic Planning for Smaller Business, Lexington, MA: D. C. Heath \& Co.

De DIOS, R.A. (1988), ASEAN Insurance and Transnationals. Paper presented at the ESCAP/ UNCTC Seminar on Service and Development: The Role of Foreign Direct Investment and Trade, Bangkok, June 7, 1988.

FREDERICK, G.D. (1983), The State of Private Sector Strategic Planning in Canada, Long Range Planning, Vol. 16(3), 1983, 40-46.

GLUCK, F.W., KAUFMAN, S.P., and WALLECK, A.S. (1980), Strategic Management for Competitive Advantage, Harvard Business Review, (July-August 1980), 154-161.

GROSJEAN, C. (1985), Strategic Planning in the European Insurance Industry in "Strategic Planning and Modelling in Property Liability Insurance", edited by J.D. Cummins, U. S. A.. Kluwer Academic Publishers, 79-103.

SHARP, E. J. (1985), Strategic Planning in the Australian Insurance Industry, in "Strategic Planning and Modelling in Property Liability Insurance", edited by J. D. Cummins, U.S. A., Kluwer Academic Publishers, 105-138.

WALKER, P. B. (1982), Strategic Management: A new Tool for Insurers Best's Review - Property/ Casualty Edition 82, (March-April), 26-34.

ZABID, A. R.M. (1987), The Nature of Managerial Work Roles in Malaysian Public Enterprises, Asia Pacific Journal of Management, Vol. 5(1), (September 1987), 16-27. 